\title{
Treatment Challenges for Inflammatory Demyelinating Polyneuropathy in the Setting of Acute Retroviral Syndrome: Case Report and Review of the Literature
}

David A Lindholm, Tatjana P Calvano, Natascha M Minidis, Thomas J Bayuk, Heather C Yun and Jason F Okulicz*

San Antonio Military Medical Center, Fort Sam Houston, Texas, USA

\begin{abstract}
This is a case of a 20 -year-old male with acute retroviral syndrome and concurrent acute inflammatory demyelinating polyneuropathy (IDP) progressing to chronic IDP. Whereas the patient followed a relapsing and remitting course prior to the initiation of antiretroviral therapy (ART), he demonstrated gradual and sustained clinical improvement in the ten months of follow-up after ART was combined with chronic corticosteroids and intermittent plasmapheresis. This case presents and addresses multiple challenges for the treatment of IDP in the setting of acute HIV infection to include: timing of initiation and selection of appropriate ART, the potential risk for immune reconstitution inflammatory syndrome, ART initiation in the setting of severe gastroparesis with jejunostomy placement, and the effect of plasmapheresis on the levels of antiretroviral therapy.
\end{abstract}

Keywords: HIV; AIDP; CIDP; Acute retroviral infection; HIV seroconversion

\section{Introduction}

The first case of Guillain-Barré Syndrome (GBS) in the setting of acute retroviral syndrome was reported in 1982 [1]. Since that time, multiple case series of acute and chronic inflammatory demyelinating polyneuropathy (IDP) associated with human immunodeficiency virus (HIV) have been reported. Although the true incidence and prevalence of inflammatory demyelinating polyneuropathies in the setting of HIV are unknown, they are believed to be rare [2]. Nevertheless, acute and chronic IDP result in significant morbidity and mortality in up to $45 \%$ of cases in resource-limited settings [1-4].

Treatment of HIV-associated IDP is derived from experience in HIV-negative patients due to the paucity of data in HIVinfected individuals. For this reason, the benefit of early initiation of antiretroviral therapy (ART) is unknown, and there is a potential risk of immune reconstitution inflammatory syndrome (IRIS) after initiation of ART [5,6]. Autonomic dysfunction is common in IDP and can lead to gastric dysmotility, which presents an additional challenge for treatment with ART. This case presents several challenges for the treatment of demyelinating polyneuropathy in the setting of acute HIV, to include considerations for ART initiation, the potential risk for IRIS, balancing the risks and benefits of ART initiation in the setting of severe gastroparesis and jejunostomy placement, and the effect of plasmapheresis on the levels of antiretroviral therapy. These issues will be addressed herein, with significant focus on treatment challenges.

\section{Case Presentation}

A 20-year-old male initially diagnosed with mononucleosis syndrome in the setting of a positive heterophile antibody, cervical lymphadenopathy, pharyngitis, and fevers, was admitted to the hospital two months after initial presentation with progressive ascending bilateral lower extremity weakness, significant upper extremity weakness, and areflexia in all four extremities. The patient had associated paresthesias of his feet and hands as well as some progressive numbness on admission. Nerve conduction studies confirmed acute IDP. HIV was suspected and confirmed during his hospitalization. His initial CD4 count was 213 cells $/ \mathrm{mm}^{3}$ (CD4\% of $11 \%$ ), and his plasma viral load (VL) was 389,000 copies $/ \mathrm{mL}$. This was believed to represent acute retroviral syndrome since he was HIV-negative on screening two months prior to the onset of his mononucleosis syndrome. Initial cerebrospinal fluid (CSF) studies revealed mild lymphocytic pleocytosis (12 leukocytes/ $\mathrm{mm}^{3}, 86 \%$ lymphocytes) and elevated protein $(119 \mathrm{mg} / \mathrm{dL})$. Qualitative cytomegalovirus (CMV) IgG and IgM titers were positive, though concurrent CSF viral culture was negative for CMV. Antivirals for CMV were not initiated, and CMV DNA was undetectable in both the serum and CSF seven weeks later.

His polyneuropathy followed a relapsing and remitting course of weakness. He was treated initially with intravenous immunoglobulin (IVIG) and systemic corticosteroids, with sufficient improvement for transfer to an inpatient rehabilitation facility. On his first relapse two weeks after presentation, he was treated with plasmapheresis, again with minor improvement and transfer to inpatient rehabilitation. One month later, he presented with respiratory failure requiring intubation and transfer to our facility. Eventually, the patient required tracheostomy due to persistent weakness of his respiratory muscles resulting in frequent intubations and difficulty liberating from the ventilator. The patient also required placement of a jejunostomy tube due to severe gastroparesis and intractable nausea and vomiting as a part of his autonomic neuropathy. He received five cycles of plasmapheresis with minimal improvement, prompting transition to IVIG, to which he responded well. Based on the duration of symptoms and relapsing nature of his IDP, the patient transitioned from acute to chronic IDP.

ART with raltegravir and tenofovir/emtricitabine was initiated two months after onset of symptoms. Initiation of ART was delayed

*Corresponding author: Jason F Okulicz, Infectious Disease (MCHE-MDI), San Antonio Military Medical Center, 3551 Roger Brooke Drive, Fort Sam Houston, Texas 78234, USA, Tel: 210-916-5554; Fax: 210-916-0388; E-mail: jason.f.okulicz.mil@mail.mil

Received August 30, 2013; Accepted November 12, 2013; Published November 17,2013

Citation: Lindholm DA, Calvano TP, Minidis NM, Bayuk TJ, Yun HC, et al. (2013) Treatment Challenges for Inflammatory Demyelinating Polyneuropathy in the Setting of Acute Retroviral Syndrome: Case Report and Review of the Literature. J AIDS Clin Res 4: 262. doi: 10.4172/2155-6113.1000262

Copyright: (c) 2013 Lindholm DA, et al. This is an open-access article distributed under the terms of the Creative Commons Attribution License, which permits unrestricted use, distribution, and reproduction in any medium, provided the original author and source are credited. 
due to the patient's severe gastroparesis and frequent plasmapheresis requirements. The patient's VL was 100,123 copies/mL at ART initiation, and he had an undetectable VL $(<20$ copies $/ \mathrm{mL})$ approximately two weeks after starting ART (Figure 1). While he experienced an additional IDP relapse approximately two weeks after initiating ART, this was attributed to the relapsing-and-remitting course of his polyneuropathy as well as the discontinuation of polyneuropathy therapy following completion of IVIG approximately three weeks earlier. Plasmapheresis and corticosteroids (prednisone $60 \mathrm{mg}$ daily) were re-initiated as part of a chronic treatment course, with ART administered after plasmapheresis sessions.

The patient demonstrated gradual clinical improvement, as evidenced by the removal of his tracheostomy and jejunostomy four months after the onset of illness, as well as the ability to ambulate with assistance six months after the onset of symptoms. On the most recent CSF analysis four months after the onset of polyneuropathy, he displayed resolved pleocytosis $\left(3\right.$ cells $\left./ \mathrm{mm}^{3}\right)$ with a persistently elevated CSF protein $(437 \mathrm{mg} / \mathrm{dL})$. He continued to receive regular, intermittent plasmapheresis twice-monthly in addition to corticosteroids until 10 months after onset of symptoms. At that time, his VL remained undetectable and CD4 count was 291 cells $/ \mathrm{mm}^{3}$ (CD4\% 20\%). To date, the patient shows continued improvement in strength, though he has some residual weakness and sensory loss as well as mild to moderate dysesthesias of the distal lower extremities. He remained on a lowdose-steroid taper twelve months after symptom onset.

\section{Discussion}

HIV infection leads to significant adverse effects on the peripheral and central nervous systems [7]. Peripheral polyneuropathy can occur at the time of seroconversion, most commonly as acute IDP [1,2,8-11]. Histopathologic changes in the brain occur within days of infection to include significant gray matter abnormalities, as can be seen in acute HIV meningoencephalitis [7]. These changes lead to neurological deficits or decreased neuropsychological functioning, which are often the only symptoms of an acute HIV infection. Peripheral neuropathies are the most frequent neurological disorder associated with HIV infection and are primarily comprised of distal sensory polyneuropathies and antiretroviral toxic neuropathies $[8,12]$. These are due to immune-mediated injuries produced by HIV infection, opportunistic infections, or direct neurotoxic effects of ART on the peripheral nervous system $[8,13]$. Although rare, IDP can cause significant morbidity and mortality [1]. Multiple mechanisms have been identified as causative factors in the development of IDP. These mechanisms all involve up-regulation of the immune system, to include T-cell stimulation and subsequent activation, humorally mediated circulating antibodies to myelin antigens, and molecular mimicry, all of which lead to inflammatory infiltration of peripheral nerves and nerve roots and subsequent demyelination $[8,13]$.

The diagnosis of IDP is established based on clinical manifestations of progressive and relapsing motor and sensory dysfunction with generalized hyporeflexia or areflexia or possible autonomic dysfunction, in combination with electrophysiologic studies demonstrating reduced conduction velocity, prolonged distal latencies, temporal dispersion, and/or conduction blocks $[2,12,14]$. CSF analysis typically reveals elevated protein due to the disruption of the blood-nerve barrier by the action of metalloproteinases. CSF pleocytosis as a predominant feature [15] is characteristic of HIV-associated IDP and distinguishes it from IDP in HIV-uninfected persons, where the CSF typically shows a pattern of albuminocytologic dissociation [2].

Treatment of IDP in the setting of HIV infection is not well known due to the rarity of the condition and lack of supporting evidence in the literature. In addition, starting critically ill patients on ART continues

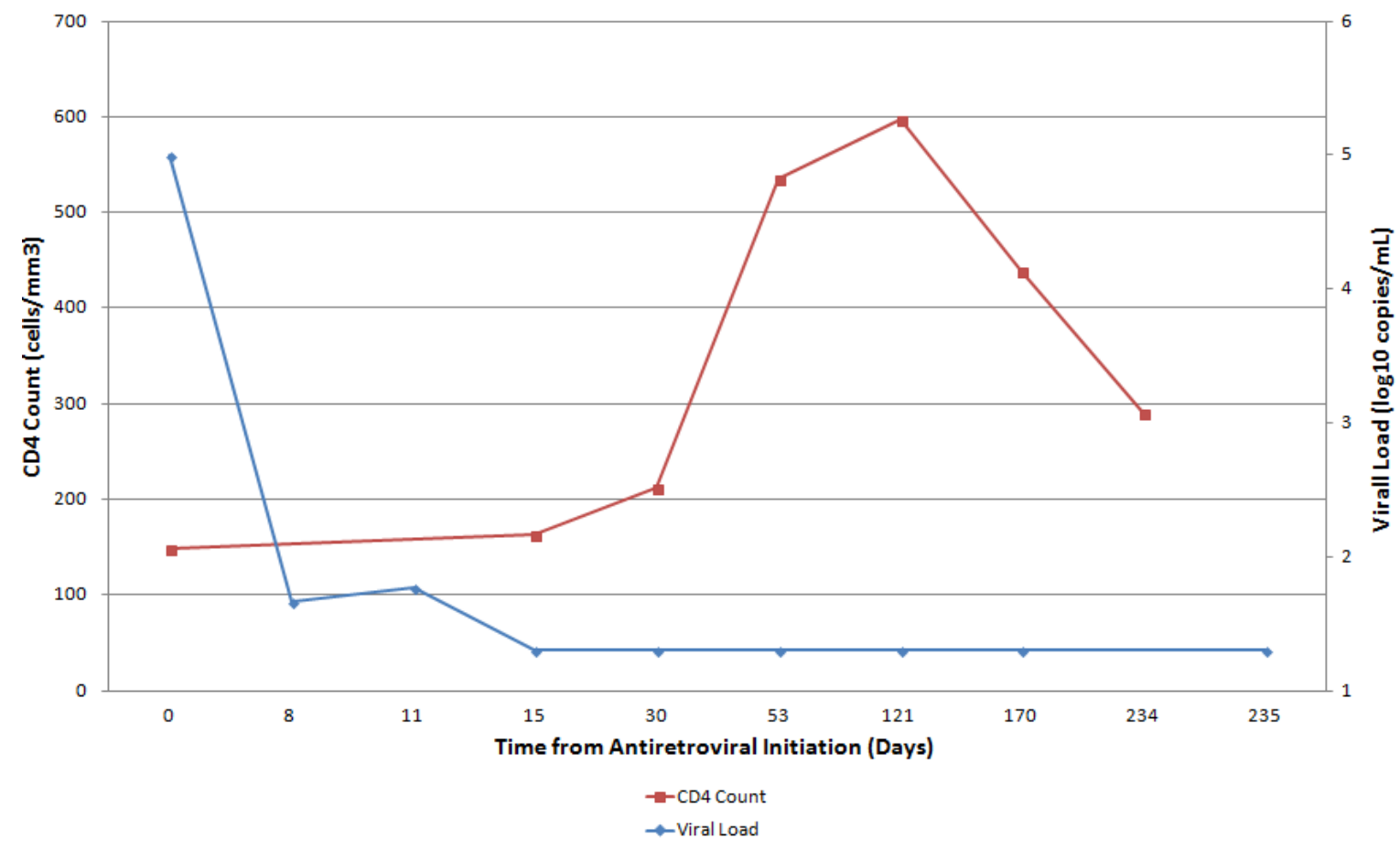

Figure 1: CD4 count and plasma viral load response after initiation of antiretroviral therapy. The viral load decreased below the limit of detection $(<20 \mathrm{copies} / \mathrm{mL})$ by treatment day 15 . 
Citation: Lindholm DA, Calvano TP, Minidis NM, Bayuk TJ, Yun HC, et al. (2013) Treatment Challenges for Inflammatory Demyelinating Polyneuropathy in the Setting of Acute Retroviral Syndrome: Case Report and Review of the Literature. J AIDS Clin Res 4: 262. doi: 10.4172/21556113.1000262

Page 3 of 7

\begin{tabular}{|c|c|c|c|c|c|c|c|}
\hline Reference & Age/Sex & $\begin{array}{c}\text { GBS } \\
\text { subtype }\end{array}$ & CD4 (cells $/ \mathrm{mm}^{3}$ ) & $\begin{array}{l}\text { IVIG } \\
\text { given }\end{array}$ & $\begin{array}{l}\text { PLEX } \\
\text { given }\end{array}$ & ART given & Outcome \\
\hline \multirow[t]{9}{*}{ Cornblath et al. [11] } & $22 \mathrm{M}$ & CIDP & Not specified & No & Yes & No & $\begin{array}{l}\text { Multiple relapses despite PLEX and prednisone; took } \\
\text { prednisone with recurrences; died of homicide months after } \\
\text { presentation }\end{array}$ \\
\hline & $31 \mathrm{M}$ & CIDP & Not specified & No & No & No & $\begin{array}{l}\text { Relapsing course; received prednisone and had resolution } \\
\text { of symptoms }\end{array}$ \\
\hline & $24 \mathrm{M}$ & CIDP & Not specified & No & No & No & Relapsing course; recovered without treatment \\
\hline & $45 \mathrm{M}$ & CIDP & Not specified & No & Yes & No & $\begin{array}{l}\text { PLEX resulted in improvement of neurological symptoms to } \\
\text { nearly normal }\end{array}$ \\
\hline & $37 \mathrm{M}$ & CIDP & Not specified & No & No & No & Recovered without treatment \\
\hline & $29 \mathrm{~F}$ & CIDP & Not specified & No & No & No & Clinical remission with prednisone \\
\hline & $18 \mathrm{M}$ & AIDP & Not specified & No & Yes & No & Improvement of symptoms \\
\hline & $27 \mathrm{M}$ & AIDP & Not specified & No & Yes & No & Improvement of symptoms \\
\hline & $26 \mathrm{M}$ & AIDP & Not specified & No & Yes & No & Improvement of symptoms \\
\hline \multirow[t]{2}{*}{ Hagberg et al. [23] } & $56 \mathrm{M}$ & AIDP & Not specified & No & No & No & $\begin{array}{c}\text { Improvement of symptoms within } 4 \text { weeks; able to walk } \\
\text { without support at } 8 \text { weeks }\end{array}$ \\
\hline & $69 \mathrm{M}$ & AIDP & Not specified & No & No & No & $\begin{array}{l}\text { On the ventilator for } 12 \text { weeks; resolution of weakness in } \\
\text { upper extremities and improvement in lower extremities } 5 \\
\text { months later }\end{array}$ \\
\hline Vendrell et al. [24] & $42 \mathrm{M}$ & AIDP & Not specified & No & Yes & No & $\begin{array}{l}\text { Improvement of motor weakness by } 4 \text { months; moderate } \\
\text { quadriparesis } 6 \text { months after symptom onset }\end{array}$ \\
\hline \multirow[t]{3}{*}{ Conlon [25] } & $28 \mathrm{~F}$ & AIDP & Not specified & No & No & No & $\begin{array}{l}\text { Died } 5 \text { weeks after symptom onset due to ventilator- } \\
\text { associated pneumonia }\end{array}$ \\
\hline & $19 \mathrm{~F}$ & AIDP & Not specified & No & No & No & $\begin{array}{l}\text { Gradual improvement over several weeks, then lost to } \\
\text { follow-up }\end{array}$ \\
\hline & $29 \mathrm{~F}$ & AIDP & Not specified & No & No & No & Able to walk with support 1 month after symptom onset \\
\hline Franciotta et al. [26] & $25 \mathrm{M}$ & AIDP & 1276 & No & Yes & No & $\begin{array}{l}\text { Partially improved neurological symptoms with moderate } \\
\text { tetraparesis } 5 \text { months after symptom onset }\end{array}$ \\
\hline \multirow[t]{2}{*}{ Qureshi et al. [13] } & $30 \mathrm{M}$ & AIDP & 5 & No & Yes & No & $\begin{array}{c}\text { Unable to walk without assistance } 1 \text { year after symptom } \\
\text { onset }\end{array}$ \\
\hline & $33 \mathrm{M}$ & AIDP & 4 & Yes & No & No & $\begin{array}{l}\text { Strength improved; required a cane to ambulate } 1 \text { year } \\
\text { after symptom onset }\end{array}$ \\
\hline $\begin{array}{l}\text { Hassan and Mathew } \\
{[27]}\end{array}$ & $27 \mathrm{M}$ & AIDP & Not specified & Yes & No & No & Complete recovery by week 4 after symptom onset \\
\hline Bani-Sadr et al. [28] & $35 \mathrm{M}$ & AIDP & 149 & No & No & $\begin{array}{l}\text { AZT/3TC/RTVI } \\
\text { IDV }\end{array}$ & Complete recovery within 2 months from ART initiation \\
\hline \multirow[t]{10}{*}{$\begin{array}{l}\text { Brannagan and Zhou } \\
\text { [20] }\end{array}$} & $\begin{array}{c}\text { Not } \\
\text { specified }\end{array}$ & AIDP & 680 & No & No & No & Good recovery with mild dysesthesias \\
\hline & $\begin{array}{c}\text { Not } \\
\text { specified }\end{array}$ & AIDP & 300 & No & Yes & No & $\begin{array}{c}\text { Good recovery; recurrent episodes developed } 4 \text { years later, } \\
\text { responding to IVIG }\end{array}$ \\
\hline & $\begin{array}{c}\text { Not } \\
\text { specified }\end{array}$ & AIDP & 430 & No & Yes & No & Full recovery \\
\hline & $\begin{array}{c}\text { Not } \\
\text { specified }\end{array}$ & AIDP & 118 & No & Yes & No & Good recovery with dysesthesias \\
\hline & $\begin{array}{c}\text { Not } \\
\text { specified }\end{array}$ & AIDP & 800 & Yes & No & No & $\begin{array}{c}\text { Good recovery - able to ambulate; recurrence } 10 \text { weeks } \\
\text { later - requires steroids and IVIG }\end{array}$ \\
\hline & $\begin{array}{c}\text { Not } \\
\text { specified }\end{array}$ & AIDP & 685 & Yes & No & No & $\begin{array}{l}\text { Good recovery; recurrence and paralysis after } 9 \text { weeks - } \\
\text { requires steroids and IVIG }\end{array}$ \\
\hline & $\begin{array}{c}\text { Not } \\
\text { Specified }\end{array}$ & AIDP & 175 & Yes & No & AZT & Died 18 days after symptom onset due to cardiac arrest \\
\hline & $\begin{array}{c}\text { Not } \\
\text { specified }\end{array}$ & AIDP & 190 & No & Yes & $\begin{array}{l}\text { Yes (regimen } \\
\text { not specified) }\end{array}$ & Good recovery with mild residual weakness \\
\hline & $\begin{array}{c}\text { Not } \\
\text { specified }\end{array}$ & AIDP & 55 & Yes & No & $\begin{array}{l}\text { Yes (regimen } \\
\text { not specified) }\end{array}$ & Good recovery with mild residual weakness \\
\hline & $\begin{array}{c}\text { Not } \\
\text { specified }\end{array}$ & AIDP & 240 & No & Yes & $\begin{array}{l}\text { Yes (regimen } \\
\text { not specified) }\end{array}$ & Weakness and reflexes recovered; dysesthesias present \\
\hline Kumar et al. [29] & $21 \mathrm{M}$ & AIDP & Not specified & No & Yes & No & $\begin{array}{l}\text { Functionally independent at 3-month follow-up; complete } \\
\text { resolution at 4-year follow-up }\end{array}$ \\
\hline Aggarwal et al. [30] & $30 \mathrm{M}$ & AIDP & 400 & No & No & No & Patient left the hospital against medical advice \\
\hline Gisslén et al. [19] & $35 \mathrm{M}$ & AIDP & 914 & Yes & No & $\begin{array}{l}\text { D4T/3TC/SQVI } \\
\quad \text { NLF }\end{array}$ & $\begin{array}{l}\text { Improvement } 3 \text { months after symptom onset; ART stopped; } \\
\text { AIDP recurred } 2 \text { months later; IVIG and ART started; } \\
\text { symptoms resolved in } 7 \text { months; ART discontinued and no } \\
\text { recurrence }\end{array}$ \\
\hline de Castro et al. [31] & $38 \mathrm{M}$ & AIDP & 502 & Yes & Yes & $\begin{array}{l}\text { AZT/3TC/IDV, } \\
\text { then AZT/3TC/ } \\
\text { RTV, then } \\
\text { AZT/3TC/EFV }\end{array}$ & $\begin{array}{l}\text { Two recurrences due to interruption of ART, followed by } \\
\text { complete recovery, which was sustained over } 3 \text { years when } \\
\text { adherent to ART }\end{array}$ \\
\hline
\end{tabular}


Citation: Lindholm DA, Calvano TP, Minidis NM, Bayuk TJ, Yun HC, et al. (2013) Treatment Challenges for Inflammatory Demyelinating Polyneuropathy in the Setting of Acute Retroviral Syndrome: Case Report and Review of the Literature. J AIDS Clin Res 4: 262. doi: 10.4172/21556113.1000262

Page 4 of 7

\begin{tabular}{|c|c|c|c|c|c|c|c|}
\hline $\begin{array}{c}\text { Wagner and Bromberg } \\
{[15]}\end{array}$ & $46 \mathrm{M}$ & AMAN & 150 & No & No & $\begin{array}{l}\text { Yes (regimen } \\
\text { not specified) }\end{array}$ & Complete recovery 12 months after symptom onset \\
\hline Hiraga et al. [32] & $56 \mathrm{M}$ & FS/GBS & 24 & Yes & No & $\begin{array}{l}\text { Yes (regimen } \\
\text { not specified) }\end{array}$ & Complete recovery with continued ART \\
\hline Sloan et al. [33] & $30 \mathrm{M}$ & AIDP & 408 & Yes & No & AZT/3TC/EFV & $\begin{array}{l}\text { Complete recovery after } 6 \text { months, even after cessation of } \\
\text { ART after } 6 \text { months }\end{array}$ \\
\hline Kumar et al. [34] & $38 \mathrm{M}$ & AIDP & 280 & Yes & No & AZT/3TC/EFV & $\begin{array}{c}\text { Death due to severe respiratory distress during initial } \\
\text { hospital stay }\end{array}$ \\
\hline Pontali et al. [35] & $56 \mathrm{M}$ & AIDP & 710 & Yes & No & No & Death on day 8 of hospital stay due to cardiac arrest \\
\hline Schreiber et al. [9] & $45 \mathrm{~F}$ & AIDP & 334 & Yes & No & No & Complete recovery 5 months after symptom onset \\
\hline Nishijima et al. [36] & $33 \mathrm{M}$ & AMAN & 334 & Yes & No & $\begin{array}{l}\text { LPV/RTV/TDF/ } \\
\text { FTC }\end{array}$ & Able to walk with a cane after 15 months of rehabilitation \\
\hline "Kume et al. [37] & $47 \mathrm{M}$ & CIDP & 466 & No & No & $\begin{array}{l}\text { Yes (regimen } \\
\text { not specified) }\end{array}$ & $\begin{array}{l}\text { Near complete recovery, with mild dysesthesias and } \\
\text { normal NCS } 6 \text { months after symptom onset; improvement } \\
\text { sustained after } 2 \text { years of follow-up }\end{array}$ \\
\hline Current case & $20 \mathrm{M}$ & AIDP & 213 & Yes & Yes & TDF/FTC/RAL & $\begin{array}{l}\text { Recurrent episodes of AIDP, with progression to CIDP; } \\
\text { near complete recovery } 12 \text { months after symptom onset }\end{array}$ \\
\hline
\end{tabular}

*Article in Japanese; data derived from English abstract.

Abbreviations: 3TC: Lamivudine; AIDP: Acute Inflammatory Demyelinating Polyneuropathy; AMAN: Acute Motor Axonal Neuropathy; ART: Antiretroviral Therapy; AZT: Zidovudine; CIDP: Chronic Inflammatory Demyelinating Polyneuropathy; D4T: Didanosine; EFV: Efavirenz; F: Female; FS: Fisher Syndrome; FTC: Emtricitabine; GBS: Guillain-Barré Syndrome; HIV: Human Immunodeficiency Virus; IDP: Inflammatory Demyelinating Polyneuropathy; IDV: Indinavir; IVIG: Intravenous Immunoglobulin; LPV: Lopinavir; M: Male; NCS: Nerve Conduction Study; NLF: Nelfinavir; PLEX: Plasmapheresis; RAL: Raltegravir; RTV: Ritonavir; SQV: Saquinavir; TDF: Tenofovir.

Table 1: Treatment of IDP in ART-naïve patients with HIV infection.

to remain a topic of debate where benefits should clearly outweigh the associated risks $[16,17]$. IDP is typically treated in the same manner as in HIV-negative patients, with IVIG, plasmapheresis, and/or corticosteroids $[2,12,14,18,19]$. Rates of recurrence are unknown in the setting of HIV, but overall recurrence rates in GBS are approximately $3 \%$ [20]. HIV-associated acute IDP manifests with more frequent and recurrent episodes, a higher likelihood of development of chronic IDP, and a prolonged duration of symptoms [8]. This appears to be associated with acute retroviral syndrome in many cases, and it can be the initial presenting symptom of HIV infection [21]. Clinical findings are similar in HIV-infected patients as in HIV-uninfected patients, except for increased need for ventilator support and mortality among individuals with HIV [3]. The prevalence of HIV in GBS-affected patients is unknown, with the prevalence ranging from zero percent in a Norwegian case series (1980-1992) to approximately 50\% in pooled case series from Sub-Saharan Africa. In the African case series, the prevalence of HIV was significantly higher in patients with GBS than it was in the population at large $[1,3,4,21]$. Multiple challenges occurred during the prolonged course of our patient's illness and are addressed in the following sections.

\section{Role of ART in the treatment of HIV-associated IDP}

The US Department of Health and Human Services (DHHS) HIV treatment guidelines recommend ART for all patients with HIV infection [22]. There are cases of complete recovery from IDP after the initiation of ART even in the absence of IVIG and plasmapheresis $[9,15]$. Reports of recurrent GBS that coincided with periods of HIV viremia due to the interruption of ART suggest that the pathophysiologic mechanisms of HIV-associated GBS are related to the control of HIV viremia. However, there are also published cases with complete recovery of HIV-associated GBS during seroconversion in the absence of ART. Review of pre-ART literature is reflective of multiple cases of GBS associated with acute HIV resulting in complete resolution of symptoms without ART. In some cases, spontaneous recovery occurred despite the absence of any treatment, such as ART, IVIG, plasmapheresis, or steroids. In other cases, however, patients continued to have relapses despite treatment. From the 42 reviewed cases of ART-naive patients with GBS, the outcomes varied regardless of which treatment was provided, as demonstrated in Table $1[9,11,13,15,19,20,23-37]$. ART is linked to both the relapse of AIDP upon its discontinuation as well as the cause of AIDP due to drug side-effects and/or IRIS [35]. Our patient did not show sustained, clinical improvement until the treatment of his underlying HIV was combined with chronic corticosteroids and intermittent plasmapheresis. Although the literature regarding the effect of ART on HIV-associated IDP is variable, our case supports the early initiation of ART in the treatment of HIV-associated IDP.

\section{Risk of IRIS with the initiation of ART in the setting of HIV- associated IDP}

Among patients with HIV-associated IDP, GBS is rarely attributed to IRIS. However, there are several cases of GBS attributed to IRIS after the initiation of ART has led to a striking increase in the CD4 cell count from a low baseline level $[5,6,38]$. The exact mechanism of GBS in this setting is unknown, but may be secondary to an aberrant immune response or adverse drug reaction [5,6]. Makela et al. [5] described a case of recurrent GBS six weeks after initiation of ART in an HIVinfected male whose CD4 cell count had increased dramatically from 86 cells $/ \mathrm{mm}^{3}$ to 510 cells $/ \mathrm{mm}^{3}$. Similarly, Piliero et al. [6] described an HIV-infected patient with AIDS who developed GBS within 26 days after the initiation of a six-drug ART regimen, which led to robust immune reconstitution, with a rise in CD4 cell count from 31 cells $/ \mathrm{mm}^{3}$ to 602 cells $/ \mathrm{mm}^{3}$. Our patient's episode of relapsing weakness 2 weeks after the initiation of ART was determined not to be a result of IRIS, as this occurred prior to immunologic recovery. Consistent with his preART course, his relapse occurred after several weeks without any IDP treatments. Ultimately, the relapsing-remitting pattern of his course was not altered until long-term co-treatment of both his HIV and IDP was initiated. Although clinicians should be aware of the potential for new or recurrent GBS in the setting of immune reconstitution, its incidence is rare and associated with a dramatic rise from a previously low $\mathrm{CD} 4$ cell count.

\section{Role of ART in the setting of severe gastroparesis and post- gastric feeding}

Further management challenges presented by our patient included the timing and selection of an effective ART regimen in the setting 
of critical illness, IDP, severe gastroparesis, and post-gastric ART administration. Challenges of ART use in the intensive care setting include drug dosage, delivery, interactions, and toxicities, as there are no randomized clinical trials or consensus guidelines to assist in decisions regarding the use of ART in this setting. The absorption of drugs is dependent on multiple factors, including gastrointestinal motility and $\mathrm{pH}$, and is often unpredictable in critically ill patients [39]. The $\mathrm{pH}$ ranges from 1 to 2 in the stomach and 7 to 8 in the jejunum, with the increased surface area of the intestinal villi conferring augmented rates of absorption as compared to the stomach [40]. Most antiretroviral medications are only available in oral formulations, with few alternative options to include intravenous formulas (namely, zidovudine), liquids, and powders. Alternatively, for medications without oral solutions, tablets may be crushed and capsules may be opened for use through a feeding tube, although it is unclear whether adequate plasma levels can be achieved in this manner [41]. In general, oral solutions are the preferred method of ART administration through feeding tubes, as the data on crushed tablets or sprinkled capsule contents are even more unreliable in terms of absorption [41]. Currently, there are no pharmacokinetic data available for the evaluation of ART when administered through a jejunostomy tube, which effectively bypasses the acidic gastric environment.

There are case reports in the literature, however, demonstrating successful administration of ART into the jejunum, as measured by detectable plasma levels of drug and a decrease in VL. Two reports demonstrated successful administration of liquid lopinavir/ritonavir into the jejunum $[42,43]$. A case series of $7 \mathrm{HIV}$-infected patients undergoing esophagojejunostomies for bariatric surgery showed maintenance of virologic suppression in all but one patient postsurgery [44].

After considering these numerous variables, we considered starting our patient on either a protease-inhibitor-based or an integraseinhibitor-based regimen in combination with the "backbone" drugs tenofovir and emtricitabine in a fixed-dose combination. Although tenofovir/emtricitabine lacks pharmacokinetic studies performed on crushed versus whole tablets, it does not have an enteric coating or sustained-release formulation that would otherwise preclude it from being crushed. The tablet is known to disintegrate in water or juices and may be consumed immediately after mixing in this manner [45].

The protease inhibitors (PIs) that were primarily considered were ritonavir-boosted lopinavir or darunavir. These PIs are both highly potent, and lopinavir/ritonavir is available in liquid form. However, lopinavir/ritonavir is lipid-soluble, thereby making it more likely to be absorbed in the stomach, particularly in the setting of food, making it a less attractive feature in our patient [46]. Although there is no data regarding darunavir absorption from the jejunum and/or the pharmacokinetic/pharmacodynamic parameters once crushed, the film-coated tablets are not sustained-release and are water-soluble, so they may be successfully crushed and dissolved in water, as was demonstrated in a case report $[47,48]$.

The integrase inhibitor raltegravir is indicated in both treatmentnaïve and -experienced patients due to its safety, significant antiviral activity, and tolerability, with few chances of drug interactions compared to other antiretrovirals [49]. Additionally, raltegravir has been shown to cause a rapid decline in the plasma VL up to a $2 \log 10$ reduction within the first two weeks of use, with resultant undetectable VL in a significant number of treated patients [50,51]. Prior studies of raltegravir pharmacokinetics had revealed erratic drug absorption and a high degree of inter- and intra-patient variability in its pharmacokinetic profile [52]. However, a 2012 study by Cattaneo et al. [52] revealed improved drug absorption and reduced interpatient pharmacokinetic variability in those who received raltegravir by chewing the tablet compared to those who swallowed the intact tablet, a difference attributed to the release of raltegravir from its pharmaceutical formulation. Two case reports have also demonstrated the successful use of raltegravir when administered through non-standard routes: one administered crushed via percutaneous endoscopic gastrostomy tube and the other administered whole through the port of a gastroduodenal tube $[53,54]$.

Considering multiple risks and benefits, we ultimately chose the raltegravir plus tenofovir/emtricitabine regimen for our patient, with a plan to repeat the VL frequently at regular intervals after initiation of therapy. Although the patient did receive his initial doses of both medications crushed via gastrojejunostomy tube, his nausea subsided concurrently and he was able to take the ART orally, mostly crushed, but consumed whole when it was safe to swallow medications.

\section{Role of ART in the setting of plasmapheresis}

Data regarding drug removal during plasmapheresis are lacking, and most publications are in the form of case reports describing the effect of plasmapheresis on pharmacologic agents used in overdose attempts [55]. The process of elimination by way of plasmapheresis is complex and takes into account numerous variables, to include plasma volume, intercompartmental equilibration, endogenous clearance, elimination rates, volume of distribution, and the protein binding of the drug [56]. Drug extraction by plasmapheresis cannot be simply or consistently calculated, nor can it be categorized into definitive or absolute terms. At a minimum, clinicians should avoid proceeding with plasmapheresis until the drug in question has had adequate time to complete its extravascular distribution [55]. In the same manner, ART is best administered immediately after a plasmapheresis session in order to minimize the potential of drug removal in preparation for subsequent plasmapheresis and to maximize drug exposure [57]. For these reasons, once-daily ART regimens are most compatible with plasmapheresis. At the time that our patient was initiated on ART, he had already completed courses of both IVIG and plasmapheresis, allowing us to dose a twice-daily ART regimen. The patient did require further plasmapheresis sessions as an outpatient, but at a frequency of twice per week, again allowing us to continue his twice-daily ART regimen.

\section{Conclusion}

IDP in the setting of HIV infection is associated with significant morbidity and mortality. Clinical outcomes in HIV-associated IDP are variable, even after ART initiation. The limited number of reported cases and the complexity of IDP in the setting of HIV lead to many challenges in the management of these conditions. Despite these challenges, this case demonstrates the successful co-treatment of HIV and IDP with ART and a multitude of interventions for IDP, including long-term steroids and intermittent plasmapheresis.

\section{References}

1. Schleicher GK, Black A, Mochan A, Richards GA (2003) Effect of human immunodeficiency virus on intensive care unit outcome of patients with GuillainBarré syndrome. Crit Care Med 31: 1848-1850.

2. Verma A (2001) Epidemiology and clinical features of HIV-1 associated neuropathies. J Peripher Nerv Syst 6: 8-13.

3. Melaku Z, Zenebe G, Bekele A (2005) Guillain-Barré syndrome in Ethiopian patients. Ethiop Med J 43: 21-26. 
Citation: Lindholm DA, Calvano TP, Minidis NM, Bayuk TJ, Yun HC, et al. (2013) Treatment Challenges for Inflammatory Demyelinating Polyneuropathy in the Setting of Acute Retroviral Syndrome: Case Report and Review of the Literature. J AIDS Clin Res 4: 262. doi: 10.4172/21556113.1000262

4. Howlett WP, Vedeler CA, Nyland H, Aarli JA (1996) Guillain-Barré syndrome in northern Tanzania: a comparison of epidemiological and clinical findings with western Norway. Acta Neurol Scand 93: 44-49.

5. Makela P, Howe L, Glover S, Ferguson I, Pinto A, et al. (2002) Recurrent Guillain-Barre syndrome as a complication of immune reconstitution in HIV. $J$ Infect 44: 47-49.

6. Piliero PJ, Fish DG, Preston S, Cunningham D, Kinchelow T, et al. (2003) Guillain-Barré syndrome associated with immune reconstitution. Clin Infect Dis 36: e111-114.

7. Ragin $A B$, Du H, Ochs R, Wu Y, Sammet CL, et al. (2012) Structural brain alterations can be detected early in HIV infection. Neurology 79: 2328-2334

8. Pardo CA, McArthur JC, Griffin JW (2001) HIV neuropathy: insights in the pathology of HIV peripheral nerve disease. J Peripher Nerv Syst 6: 21-27.

9. Schreiber AL, Norbury JW, De Sousa EA (2011) Functional recovery of untreated human immunodeficiency virus-associated Guillain-Barré syndrome: a case report. Ann Phys Rehabil Med 54: 519-524.

10. Lipkin WI, Parry G, Kiprov D, Abrams D (1985) Inflammatory neuropathy in homosexual men with lymphadenopathy. Neurology 35: 1479-1483.

11. Cornblath DR, McArthur JC, Kennedy PG, Witte AS, Griffin JW (1987) Inflammatory demyelinating peripheral neuropathies associated with human T-cell lymphotropic virus type III infection. Ann Neurol 21: 32-40.

12. Ferrari S, Vento S, Monaco S, Cavallaro T, Cainelli F, et al. (2006) Human immunodeficiency virus-associated peripheral neuropathies. Mayo Clin Proc 81: $213-219$

13. Qureshi AI, Cook AA, Mishu HP, Krendel DA (1997) Guillain-Barré syndrome in immunocompromised patients: a report of three patients and review of the literature. Muscle Nerve 20: 1002-1007.

14. Robinson-Papp J, Simpson DM (2009) Neuromuscular diseases associated with HIV-1 infection. Muscle Nerve 40: 1043-1053.

15. Wagner JC, Bromberg MB (2007) HIV infection presenting with motor axona variant of Guillain-Barré Syndrome. J Clin Neuromuscul Dis 9: 303-305.

16. Meybeck A, Lecomte L, Valette M, Van Grunderbeeck N, Boussekey N, et al (2012) Should highly active antiretroviral therapy be prescribed in critically ill HIV-infected patients during the ICU stay? A retrospective cohort study. AIDS Res Ther 9: 27

17. Soni N, Pozniak A (2001) Continuing HIV therapy in the ICU. Crit Care 5: 247248.

18. Wulff EA, Wang AK, Simpson DM (2000) HIV-associated peripheral neuropathy: epidemiology, pathophysiology and treatment. Drugs 59: 1251-1260

19. Gisslén M, Fredman P, Fuchs D, Lekman A, Rosengren L (2005) Temporarily controlled HIV-1 replication after intravenous immunoglobulin treatment of Guillain-Barré syndrome. Scand J Infect Dis 37: 877-881.

20. Brannagan TH 3rd, Zhou Y (2003) HIV-associated Guillain-Barré syndrome. J Neurol Sci 208: 39-42.

21. Thornton CA, Latif AS, Emmanuel JC (1991) Guillain-Barré syndrome associated with human immunodeficiency virus infection in Zimbabwe. Neurology 41: 812-815

22. AIDS info (2013) Guidelines for the use of antiretroviral agents in HIV-1infected adults and adolescents. Panel on Antiretroviral Guidelines for Adults and Adolescents, Department of Health and Human Services.

23. Hagberg L, Malmvall BE, Svennerholm L, Alestig K, Norkrans G (1986) Guillain-Barré syndrome as an early manifestation of HIV central nervous system infection. Scand J Infect Dis 18: 591-592.

24. Vendrell J, Heredia C, Pujol M, Vidal J, Blesa R, et al. (1987) Guillain-Barré syndrome associated with seroconversion for anti-HTLV-III. Neurology 37: 544

25. Conlon CP (1989) HIV infection presenting as Guillain-Barre syndrome in Lusaka, Zambia. Trans R Soc Trop Med Hyg 83: 109.

26. Franciotta DM, Brustia R, Minoli L, Bono G, Ceroni M, et al. (1992) Acute Guillain-Barré syndrome associated with asymptomatic HIV infection. Acta Neurol (Napoli) 14: 66-70

27. Hassan KM, Mathew I (2000) Guillain Barre' syndrome--in an HIV seropositive subject. J Assoc Physicians India 48: 1214.
28. Bani-Sadr F, Neuville S, Crassard I, Guihot A, Molina JM (2002) Acute GuillainBarré syndrome during the chronic phase of HIV infection and dramatic improvement under highly active antiretroviral therapy. AIDS 16: 1562.

29. Kumar S, Alexander M, Markandeyulu V, Gnanamuthu C (2003) Guillain-Barre syndrome presenting in the anti-HIV seroconversion period. Neurol India 51 : 559 .

30. Aggarwal HK, Chakrabarti D, Nand N, Sonia, Bharti K, et al (2005) HIV infection presenting as Guillain-Barré syndrome. JIACM 6: 341-342.

31. de Castro G, Bastos PG, Martinez R, de Castro Figueiredo JF (2006) Episodes of Guillain-Barré syndrome associated with the acute phase of HIV-1 infection and with recurrence of viremia. Arq Neuropsiquiatr 64: 606-608.

32. Hiraga A, Kuwabara S, Nakamura A, Yuki N, Hattori T, et al. (2007) Fisher/ Gullain-Barré overlap syndrome in advanced AIDS. J Neurol Sci 258: 148-150.

33. Sloan DJ, Nicolson A, Miller AR, Beeching NJ, Beadsworth MB (2008) Human immunodeficiency virus seroconversion presenting with acute inflammatory demyelinating polyneuropathy: a case report. J Med Case Rep 2: 370.

34. Kumar N, Pandey K, Das VN, Sinha PK, Topno RK, et al. (2008) HIV infection, visceral leishmaniasis and Guillain-Barré syndrome in the same patient: a case report. Ann Trop Med Parasitol 102: 185-188.

35. Pontali E, Feasi M, Crisalli MP, Cassola G (2011) Guillain-Barré Syndrome with Fatal Outcome during HIV-1-Seroconversion: A Case Report. Case Rep Infect Dis 2011: 972096.

36. Nishijima T, Tsukada K, Takeuchi S, Chiba A, Honda M, et al. (2011) Antiretrovira therapy for treatment-naïve chronic HIV-1 infection with an axonal variant of Guillain-Barré syndrome positive for anti-ganglioside antibody: a case report. Intern Med 50: 2427-2429.

37. Kume K, Ikeda K, Kamada M, Touge T, Deguchi K, et al. (2013) Successfu treatment of HIV-associated chronic inflammatory demyelinating polyneuropathy by early initiation of highly active anti-retroviral therapy. Rinsho Shinkeigaku 53: 362-366.

38. Puthanakit T, Oberdorfer P, Akarathum N, Wannarit P, Sirisanthana T, et al (2006) Immune reconstitution syndrome after highly active antiretroviral therapy in human immunodeficiency virus-infected thai children. Pediatr Infect Dis J 25: 53-58.

39. Schanker LS, Shore PA, Brodie BB, Hogben CA (1957) Absorption of drugs from the stomach. I. The rat. J Pharmacol Exp Ther 120: 528-539.

40. Miller AD, Smith KM (2006) Medication and nutrient administration considerations after bariatric surgery. Am J Health Syst Pharm 63: 1852-1857.

41. Huang L, Quartin A, Jones D, Havlir DV (2006) Intensive care of patients with HIV infection. N Engl J Med 355: 173-181.

42. Boffito M, Lucchini A, Maiello A, Dal Conte I, Hoggard PG, et al. (2003) Lopinavir/ritonavir absorption in a gastrectomized patient. AIDS 17: 136-137.

43. Kamimura M, Watanabe K, Kobayakawa M, Mihara F, Edamoto Y, et al. (2009) Successful absorption of antiretroviral drugs after gastrojejunal bypass surgery following failure of therapy through a jejunal tube. Intern Med 48: 1103-1104.

44. Selke H, Norris S, Osterholzer D, Fife KH, DeRose B, et al. (2010) Bariatric surgery outcomes in HIV-infected subjects: a case series. AIDS Patient Care STDS 24: $545-550$

45. Truvada (emtricitabine/tenofovir disoproxil fumarate) [package insert]. Foster City, CA.

46. Kaletra (lopinavir/ritonavir) [package insert]. North Chicago, IL.

47. Prezista (darunavir) [package insert]. Titusville, $\mathrm{NJ}$.

48. Scholten S, Mauruschat S, Hindermann S, Ranneberg B (2010) Administration of darunavir tablets in patients with difficulties in swallowing - two case reports. J Int AIDS Soc 13: p114

49. Eron JJ, Young B, Cooper DA, Youle M, Dejesus E, et al. (2010) Switch to a raltegravir-based regimen versus continuation of a lopinavir/ritonavirbased regimen in stable HIV-infected patients with suppressed viraemia (SWITCHMRK 1 and 2): two multicentre, double-blind, randomised controlled trials. Lancet 375: 396-407.

50. Markowitz M, Morales-Ramirez JO, Nguyen BY, Kovacs CM, Steigbigel RT, et al. (2006) Antiretroviral activity, pharmacokinetics, and tolerability of MK0518, a novel inhibitor of HIV-1 integrase, dosed as monotherapy for 10 days in treatment-naive HIV-1 infected individuals. J Acquir Immune Defic Syndr 43 : 509-515. 
Citation: Lindholm DA, Calvano TP, Minidis NM, Bayuk TJ, Yun HC, et al. (2013) Treatment Challenges for Inflammatory Demyelinating Polyneuropathy in the Setting of Acute Retroviral Syndrome: Case Report and Review of the Literature. J AIDS Clin Res 4: 262. doi: 10.4172/21556113.1000262

51. Markowitz M, Nguyen BY, Gotuzzo E, Mendo F, Ratanasuwan W, et al. (2007) Rapid and durable antiretroviral effect of the HIV-1 integrase inhibitor raltegravir as part of combination therapy in treatment-naive patients with HIV-1 infection: results of a 48-week controlled study. J Acquir Immune Defic Syndr 46: 125133.

52. Cattaneo D, Baldelli S, Cerea M, Landonio S, Meraviglia P, et al. (2012) Comparison of the in vivo pharmacokinetics and in vitro dissolution of raltegravir in HIV patients receiving the drug by swallowing or by chewing. Antimicrob Agents Chemother 56: 6132-6136.

53. Sandkovsky U, Swindells S, Moore R, Acosta EP, Fletcher CV (2012) Acceptable plasma concentrations of raltegravir and etravirine when administered by gastrostomy tube in a patient with advanced multidrug-resistant human immunodeficiency virus infection. Pharmacotherapy 32: 142-147.
54. Taegtmeyer AB, Müller V, Kovari H, Kullak-Ublick GA, Corti N (2011) Effect of continuous venovenous hemodiafiltration on darunavir and raltegravir exposure after administration via a gastroduodenal tube. AIDS 25: 1339-1341.

55. Ibrahim RB, Liu C, Cronin SM, Murphy BC, Cha R, et al. (2007) Drug removal by plasmapheresis: an evidence-based review. Pharmacotherapy 27: 15291549

56. Nenov VD, Marinov P, Sabeva J, Nenov DS (2003) Current applications of plasmapheresis in clinical toxicology. Nephrol Dial Transplant 18: v56-58.

57. Hart D, Sayer R, Miller R, Edwards S, Kelly A, et al. (2011) Human immunodeficiency virus associated thrombotic thrombocytopenic purpura favourable outcome with plasma exchange and prompt initiation of highly active antiretroviral therapy. Br J Haematol 153: 515-519. 